

\title{
Seafloor segmentation using angular backscatter responses obtained at sea with a forward-looking sonar system
}

Stelio Haniotis, Pierre Cervenka, Carlos Negreira, Jacques Marchal

\section{- To cite this version:}

Stelio Haniotis, Pierre Cervenka, Carlos Negreira, Jacques Marchal. Seafloor segmentation using angular backscatter responses obtained at sea with a forward-looking sonar system. Applied Acoustics, 2015, 89, pp.306-319. 10.1016/j.apacoust.2014.09.025 . hal-01089856

\section{HAL Id: hal-01089856 \\ https: / hal.sorbonne-universite.fr/hal-01089856}

Submitted on 2 Dec 2014

HAL is a multi-disciplinary open access archive for the deposit and dissemination of scientific research documents, whether they are published or not. The documents may come from teaching and research institutions in France or abroad, or from public or private research centers.
L'archive ouverte pluridisciplinaire HAL, est destinée au dépôt et à la diffusion de documents scientifiques de niveau recherche, publiés ou non, émanant des établissements d'enseignement et de recherche français ou étrangers, des laboratoires publics ou privés. 


\title{
Seafloor segmentation using angular backscatter responses obtained at sea with a forward-looking sonar system
}

\author{
Stelio Haniotis, ${ }^{\mathrm{a}, \mathrm{b}}$ Pierre Cervenka, ${ }^{\mathrm{b}}$ Carlos Negreira ${ }^{\mathrm{a}}$ and Jacques Marchal ${ }^{\mathrm{b}}$ \\ (a) Universidad de la República, Facultad de Ciencias, Igua 4225, Montevideo 11400, Uruguay. \\ (b) UPMC Univ Paris 06, CNRS, UMR 7190, Institut Jean le Rond d'Alembert, \\ 2 Place de la gare de Ceinture, 78210 Saint-Cyr-l'Ecole, France.
}

http://dx.doi.org/10.1016/j.apacoust.2014.09.025

\begin{abstract}
Segmentation of the seabed is addressed by exploiting the local angular backscatter acoustic responses of the bottom. The study is based on data collected at sea with an experimental front-scan sonar system (COSMOS - Project partially funded by the European Commission in the MAST III program - Contract $n^{\circ}$ MAS3-CT97-0090 - DG12 - ESCY). Data were recorded during a three day survey in the Mediterranean Sea in high variability sediment areas. The front-looking geometry of the COSMOS system enables the collection of the local angular responses of the bottom over a wide range of incidence angles. The angular responses are projected on a principal components basis and subsequently classified by means of a density-based cluster identification method. The resulting segmentation maps delineate properly homogeneous zones of the seafloor that are in agreement with the ground-truth information provided by samples collected at sea.
\end{abstract}

\section{Keywords}

Forward looking sonar; Sediment backscatter angular response; Segmentation; Clustering; Classification

\section{Introduction}

Knowledge regarding the type of seabed is of interest to various groups and organizations, including those that concern defense (mine countermeasures), the environment (habitat mapping and protection), the economy (fishing, mining), and maritime issues (dredging of harbors and channels). The analysis of core samples and video observations provide an accurate characterization of the seafloor. However, the collection of such observations is a time consuming, and therefore costly, process, which can give only a very sparse sampling of the surveyed areas. Acoustic methods offer an alternative to these direct methods. Efforts tend toward the automatic classification and segmentation of the seafloor, attempting to establish an optimized balance between the reliability of the results and the large amount of saved time when covering large areas.

The methods that are developed depend on the geometry and the performance of the acoustical systems of acqui- sition. The algorithms are usually model-based by matching the signals acquired at sea with the output of models that mimic the measurement setup [1]-[8]. Our interest is restricted to the acoustic methods for seafloor characterization based on sonar systems. With systems delivering backscattering images (e.g., sidescan sonar systems), several algorithms, mostly based on textural analysis, attempt to provide the automatic discrimination of seafloor classes and segmentation maps [9]-[17]. A different approach is carried out when the incident angle of the backscattered echoes from the seafloor is known (e.g., with multibeam echosounders). The angular response depends on the geological/biological nature and upper morphology of the seabed, such as the roughness of the water/sediment interface and the volume structure of the sediment. This dependency is exploited to classify the seafloor [17]-[26]. A bibliography listing references to papers, reports, abstracts and proceedings dealing with seabed classification or habitat mapping using acoustic techniques, is in [27]. 
Classical surveying systems (sidescan sonar and multibeam echo sounders) scan the seafloor along successive bands in the across-track direction [28]-[30]. Hence, each individual patch of the seafloor is observed under very few incidence angles [19], [31] because usual operating conditions do not provide much overlap of the seafloor coverage. It is difficult to infer the angular backscatter responses: measurements are spatially scattered, which implies assessing homogeneous areas by searching for responses that match reference models (e.g., theoretical sediment models).

The prototype of a forward-looking multi-beam sonar system has been developed within the European MAST III program (COSMOS Project - Contract no. MAS3-CT970090) [32]. The COSMOS system was designed for studying innovative ways of observing and analyzing the seafloor (backscatter imaging [33], bathymetry [34], and characterization). Because of the forward geometry (Fig. 1 ), the same parts of the bottom are repeatedly insonified under different incidence angles while the sonar is moving forward. This overlap provides the unique capability to map the local angular dependence of the backscattered strength. The question addressed here is the feasibility of performing a blind classification when this information is available. The potential interest is the possibility to achieve preliminary segmentation without needing a sonar system whose sensitivity is calibrated.

The COSMOS system is described in section 2. The main steps in the conditioning of the recorded data leading to multilayered backscatter images (i.e., sorted by grazing angles) are also addressed. Section 3 is devoted to the practical problems involved in sorting the angles of view. The distribution of the angular sampling is studied. The binning of the selected angular range is designed to optimize the amount of complete angular responses. To keep the processes as simple as possible, the acoustic data are not draped on a sophisticated numerical terrain model. One uses, instead, a local plane bottom assumption. However, it is shown that the resulting errors and biases are not critical if the relief is smooth enough. Section 4 describes the classification process; it is performed in the space derived from a Principal Component Analysis, and clusters of angular responses are detected and merged to form classes. Section 5 presents the experimental results. Segmentation maps built with data acquired at sea are shown. Ground truth is addressed by using sample data provided by Instituto de Ciencias del Mar (ICM) of Barcelona and samples collected in the COSMOS campaign. Limits and perspectives of this study are discussed in the conclusions (Section 6).

\section{COSMOS System}

\subsection{General description}

The COSMOS system is a forward-looking sonar whose dimensions and range capabilities are sized by the
$100 \mathrm{kHz}$ central frequency. The maximal slant range is thus a few hundred meters. The main difference from most of the off-the-shelf forward-looking systems is the shape of the solid angle covered by the acoustic beams (Fig. 1): the aperture in elevation is large $\left(>80^{\circ}\right)$, starting from near nadir to near horizontal; the aperture in azimuth is limited to $2 \phi_{\max } \approx 25^{\circ}$. This design is meant to obtain a large coverage for the backscatter angular responses of the seafloor over the along-track central band that is surveyed.
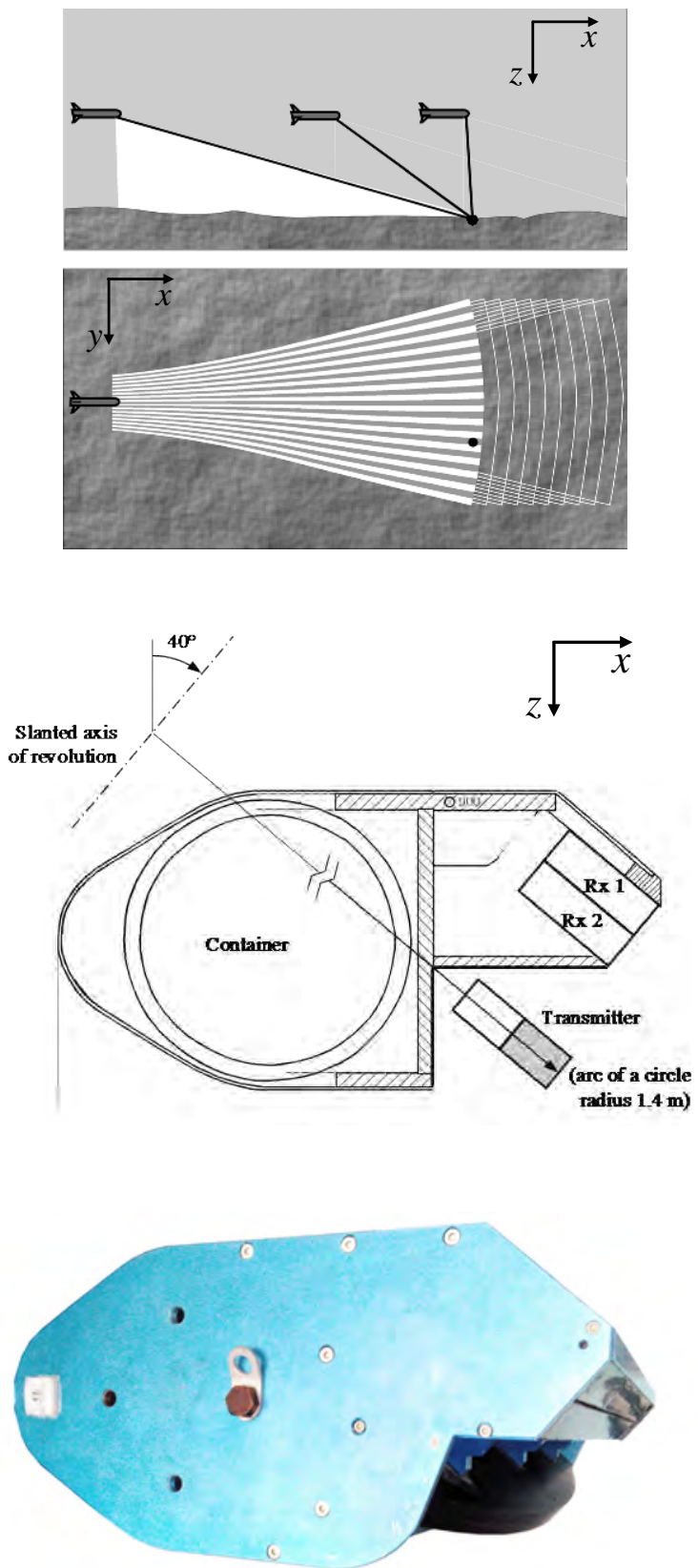

Fig. 1.(a) schematic representation of the COSMOS beams pattern.

(b) partial cross section of the sonar system. The active face of the transmitter is shaded; $\mathrm{Rx} 1$ and $\mathrm{Rx} 2$ denote the receiving antennas. (c) COSMOS downside unit.

The transmitting antenna is a circular arc, $80 \mathrm{~cm}$ long with a $1.4 \mathrm{~m}$ radius. The plane of the circle is slanted $40^{\circ}$ 
below the horizontal. The transmitted beam pattern is thus about $0.8 / 1.4 \mathrm{rad} \approx 32^{\circ}$ in the plane of the arc, and decreases when elevation departs from $40^{\circ}$. The measured source level is $207 \mathrm{~dB}$ re $1 \mu \mathrm{Pa}_{\mathrm{rms}} @ 1 \mathrm{~m}$.

The receiving antenna consists of two parallel linear arrays to allow beamforming in azimuth and to enable interferometric measurements (elevation angle). The boresight direction of the receiving antenna is slanted at the same angle as the transmitting antenna $\left(40^{\circ}\right)$. The length of each array is $72 \mathrm{~cm}$ (32 elements with a pitch of $22.5 \mathrm{~mm}$ ). In the frequency band around $100 \mathrm{kHz}$, this geometry gives an angular resolution in azimuth of $\Delta \phi \approx 1 / 48 \mathrm{rad} \approx 1^{\circ}$ at $-3 \mathrm{~dB}$ (the array length is 48 wavelengths). The formation of 31 beams is then sufficient to fully cover the total aperture in azimuth.

The transmitted signal is a linear frequency modulated pulse (chirp) whose amplitude is shaded by a truncated Gaussian window (20\% of max amplitude at the ends). The bandwidth is $B=3 \mathrm{kHz}$ and the Chirp duration is $8 \mathrm{~ms}$. Thus, the echographic radial resolution $\delta r \approx c /(2 B)$ obtained after pulse compression is approximately $25 \mathrm{~cm}$. A comprehensive description of the COSMOS system can be found in [33].

\subsection{Data preprocessing}

\subsubsection{Signal processing and beamforming}

The digitized signals received from the array elements are processed to build sets of beamformed data that are eventually used in studies on backscatter imaging, bathymetry, and seafloor characterization. The main steps of the process are:

- compensation based on the calibration of each element (amplitude and phase);

- removal of the time varying gain (TVG) that was applied in-line;

- pulse compression;

- beam-forming with dynamic focusing using the Fresnel approximation (31 beams per receiving array);

- correction to compensate for propagation losses;

- coding of the data to reduce significantly the size of the post-processed files;

- search for the instant of the first bottom echoes;

- $\quad$ estimate of the maximal useful range (related to signal-to-noise ratio);

- synchronization and interpolation of navigation and attitude information.

The propagation losses and the size of the insonified footprint contribute to the evolution of the backscattered intensities according to the law:

$$
A_{\text {echo }} \propto \frac{\exp (-4 \alpha r)}{r^{3}} \frac{\Delta \phi \delta r}{\cos \gamma}
$$

where $r$ is the range, $\alpha$ is the absorption coefficient and $\gamma$ is the grazing angle. At this stage of the processing, the relief is not known. Consequently, the time evolution of the grazing angle is not known either. Hence, the multiplicative factor that is actually applied (in terms of amplitudes) before archiving the beamformed data is based on the only part of equation (1) that depends on range, i.e., $\exp (2 \alpha r) r^{3 / 2}(\Delta \phi \delta r)^{-1 / 2}$. This correction is mandatory to enable the comparison of angular responses from the bottom at depths that differ. On the other hand, no correction depending on the directivity patterns of the antennae (elevation angle) is performed. This is justified because the classification scheme presented here does not rely on a comparison with the theoretical angular backscatter indexes of sediments.

\subsubsection{Projection}

The bottom is assumed to locally be a horizontal plane for mapping the beamformed acoustic data. For each ping, the reference altitude of the antennae is estimated with the delay of arrival of the first bottom return that is derived in processing the central beam. Because of the slow ship speed ( $V \approx 3$ knots), the Doppler effect is neglected. The surveyed area is in shallow waters thus the refraction is neglected as well (the measured sound speed variation is less than $0.3 \%$ in the water column). Attitude and navigation data are synchronized with acoustic data. The process includes interpolations based on the least-squares fitting method. For each ping, a single set of non-acoustic data is computed at the time of the pulse transmission. The mapping process is handled with the stop and hop scenario (i.e., the system is assumed to be static during every ping), which leads to a horizontal placement bias smaller than half the translation of the ship between ping transmit and echo receive. With a maximal slant range of $300 \mathrm{~m}$ (roundtrip delay $\Delta t \approx 400 \mathrm{~ms}$ ), the upper limit of the along-track bias is $V \Delta t / 2=30 \mathrm{~cm}$ (with $V=3$ knots), i.e., less than the chosen grid pitch $(40 \mathrm{~cm})$.

\subsubsection{Multilayered imaging}

In the process of projecting the backscattered echoes as described above, with the horizontal, flat bottom assumption - into geo-referenced mosaic images, an approximation of the local grazing angle of each data point is available. The main interest of the geometry of acquisition is the multiplicity of the angles of view afforded by the large overlap between the sectors scanned during successive pings. Hence, the acoustic data are sorted into a multilayered map, with each layer corresponding to a small range of grazing angles. Within each layer, beamformed data filling the same pixel are merged (intensity average). Thus, each layer provides a backscatter image of the bottom observed under a restricted range of grazing angle.

For control purposes, all of these layers are eventually merged as described in [33] to provide a single global image. 


\section{Angular sampling of the bottom}

\subsection{Distribution of the surveyed grazing angles}

Let us consider a right-handed coordinate system $(\mathrm{O}, \mathbf{x}, \mathbf{y}, \mathbf{z})$. The antennas are located at the origin $\mathrm{O}$, with the linear arrays being oriented along the $y$-axis. The $z$-axis is vertical and oriented downward. The $x$-axis is directed horizontally along the trajectory of the sonar. Each beam steered at an angle $\phi$ emphasizes the reception of echoes coming from the cone defined by the $y$-axis and the apex angle $\pi / 2-\phi$ (Fig. 2).

Assuming a plane horizontal floor at depth $h$, the complete ping footprint is limited across-track by the hyperbolae corresponding to the maximum steering angles $\left|\phi_{\max }\right| \approx 12.5^{\circ}$ (Fig. 3-bottom). Hence, the width of the scanned sector ranges from $2 y_{\min }=2 h \tan \phi_{\max } \approx 0.4 h$ at the nadir of the sonar, up to $2 y_{\min }=2 h \sin \phi_{\max } / \sin \gamma_{\min }$ at the minimum grazing angle, $\gamma_{\min }$. When $\gamma_{\min }$ and $\phi_{\max }$ share the same order of magnitude, the maximal width of the ping footprint is around the water depth, i.e., $2 y_{\min } \approx 2 h$. The minimum grazing angle, $\gamma_{\min }$, depends mostly on the signal-to-noise ratio that characterizes a maximal useful range $r_{\max }$, i.e., $\gamma_{\min }=\arcsin \left(h / r_{\max }\right)$. With $r_{\max }=300 \mathrm{~m}$ and $h=40 \mathrm{~m}$, it gives $\gamma_{\min }=8^{\circ}$.

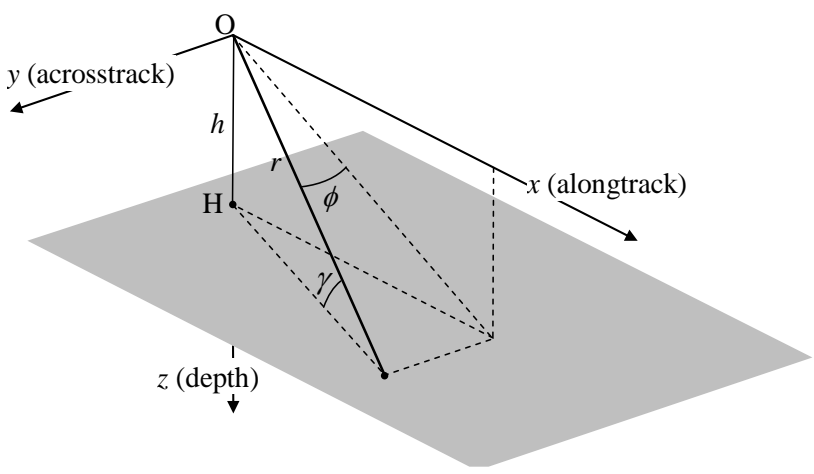

Fig. 2. Geometry of acquisition. When steering a beam at angle $\phi$ with a receiving linear array located along the $y$-axis, the directions of maximal sensitivity are given by the cone defined by the y-axis and the apex angle $\pi / 2-\phi$. The intersection of this cone with a plane bottom draws a hyperbola.

The reverberation caused by multiple echoes between the surface and the bottom contributes also to reduce the signal-to-noise ratio. With the antennae being located at depth $d$ below the surface (4 $\mathrm{m}$ with the settings of the survey) and altitude $h$ above the bottom, the first multiple is embedded with backscattered echoes coming from the grazing angle $\gamma_{c}=\arcsin [h /(2 h+d)]$. Whatever is the value of $h$, there is always $\gamma_{c} \leq 30^{\circ}$. These interferences have a dramatic effect on the phase measurements that cannot be performed with the interferometer below this critical angle. However, no evidence has been found of a significant statistical bias in the backscattered intensities caused by this phenomenon. Practically, the noise levels inferred from the evolution of the backscattered echoes with range led to choose the conservative value $\gamma_{\text {min }}=14^{\circ}$ in our analysis of the angular responses.

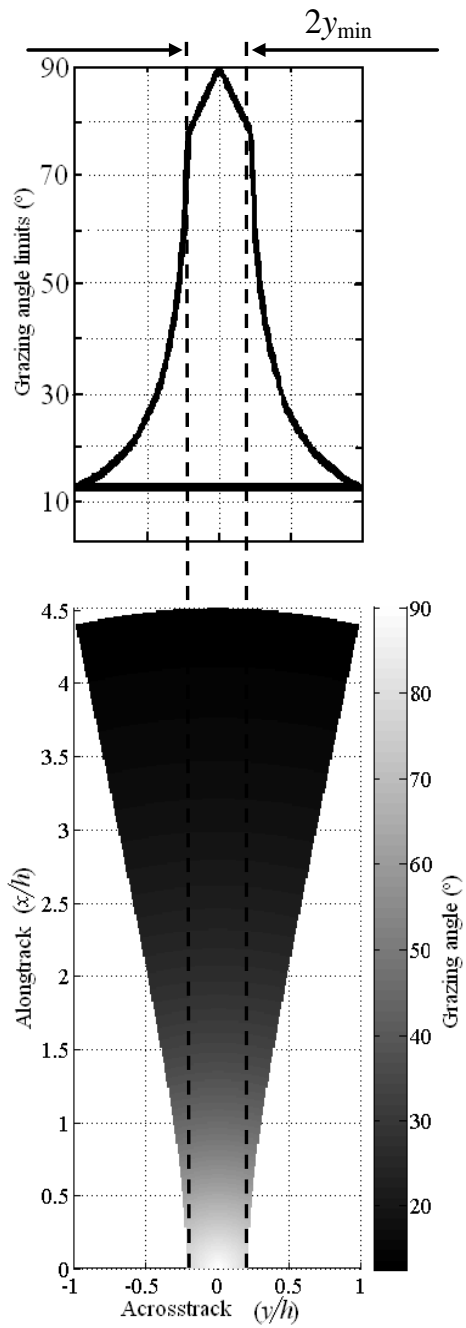

Fig. 3. (Top) limit of the accessible grazing angle in function of dimensionless across-track position $y / h$. (Bottom) Print of a ping in function of grazing angle (grey scale).

The range of grazing angles, under which a point of the floor is observed as the sonar moves ahead, depends on its lateral position, $y$ (Fig. 3-top). The largest ranges are obtained in the central band $\left(|y| \leq y_{\min }\right)$, with $\gamma \in\left[\gamma_{\min }, \pi / 2-\arctan (y / h)\right]$. Out of this band, i.e., with $|y| \leq\left[y_{\min }, y_{\max }\right]$, the range of grazing angles decreases $\gamma \in\left[\gamma_{\min }, \arcsin \left(h \sin \phi_{\max } / y\right)\right]$. The narrowest interval is reached at the maximal lateral distance $|y|=y_{\max }$, for which the bottom is observed only once, at the grazing angle $\gamma_{\text {min }}$.

\subsection{Angular bining}

The different angles of view are generated by the translation of the sonar. Because of the discrete steps involved by the sequential pings, the angular sampling of the bottom within the ranges described in the previous section is not continuous. We are looking here at the optimal binning of 
the grazing angles $\left\{\gamma_{i}\right\}$ used to sort the backscatter angular responses, to provide a gapless coverage.

The trajectory of the platform is assumed to be a straight line, with the forward step being a constant, $\Delta x$, between successive pings. For the sake of clarity, one considers the stop and hop scenario. In addition, the angular sampling is studied in the vertical plane that contains the platform track, the ground profile being horizontal, at depth $h$ below the antenna.

A point of the bottom lying at the abscissa $x$ ahead of the sonar nadir $(y=0)$ during a ping is viewed under the grazing angle $\gamma=\pi / 2-\arctan (x / h)$. Because $\Delta x \ll h$, the change between successive pings in the angle of view of the same area is approximately $\Delta \gamma \approx(\Delta x / h) \sin ^{2} \gamma$ (Fig. 4).



Fig. 4. Variation in the angles of view $\Delta \gamma$ and binning $\delta \gamma$ (case $\delta \gamma<\Delta \gamma$ )

To provide a gapless angular sampling of the bottom, the longitudinal extent $\delta x$ of the segments intercepted on the bottom by the sectors $\delta \gamma$ corresponding to the bin that contains the grazing angle $\gamma$ must be larger than the forward step $\Delta x$ of the sonar between pings, i.e., there must be $\delta \gamma \geq \Delta \gamma$. An upper bound of the bin widths is given by the change of view of the nadir area, $\Delta \gamma \approx \Delta x / h$. With data acquired at sea, the distance $\Delta x$ is typically a few meters, and the water level, $h$, is a few tens of meters. Statistics made on the processed surveys yield the order of magnitude $\Delta \gamma_{\max }=1 / 12 \approx 5^{\circ}$. Given an initial grazing angle $\gamma_{0}\left(=69^{\circ}\right)$, the first part of the partition is thus built recursively by considering constant longitudinal footprints, i.e., $\cot \gamma_{i+1}-\cot \gamma_{i} \approx \Delta \gamma_{\max }$ :

$$
\gamma_{i}=\operatorname{arccot}\left(\cot \gamma_{0}+i \Delta \gamma_{\max }\right)
$$

so that $\delta \gamma_{i+1}=\gamma_{i}-\gamma_{i+1} \approx \Delta \gamma_{\max } \sin ^{2} \frac{\gamma_{i+1}+\gamma_{i}}{2}$.

For low grazing angles, the width of the bins dictated by a constant longitudinal interval $\delta x=\Delta x$ turns out to be very small, which is not justified by the experimental accuracy and increases unnecessarily the number of bins. Consequently, the second part of the partition is built with a constant angular bin width when it reaches a chosen threshold, $\delta \gamma_{\text {end }}=2^{\circ}$ (Fig. 5). The resulting grazing angles at the limit of the bins are displayed in Fig. 6.

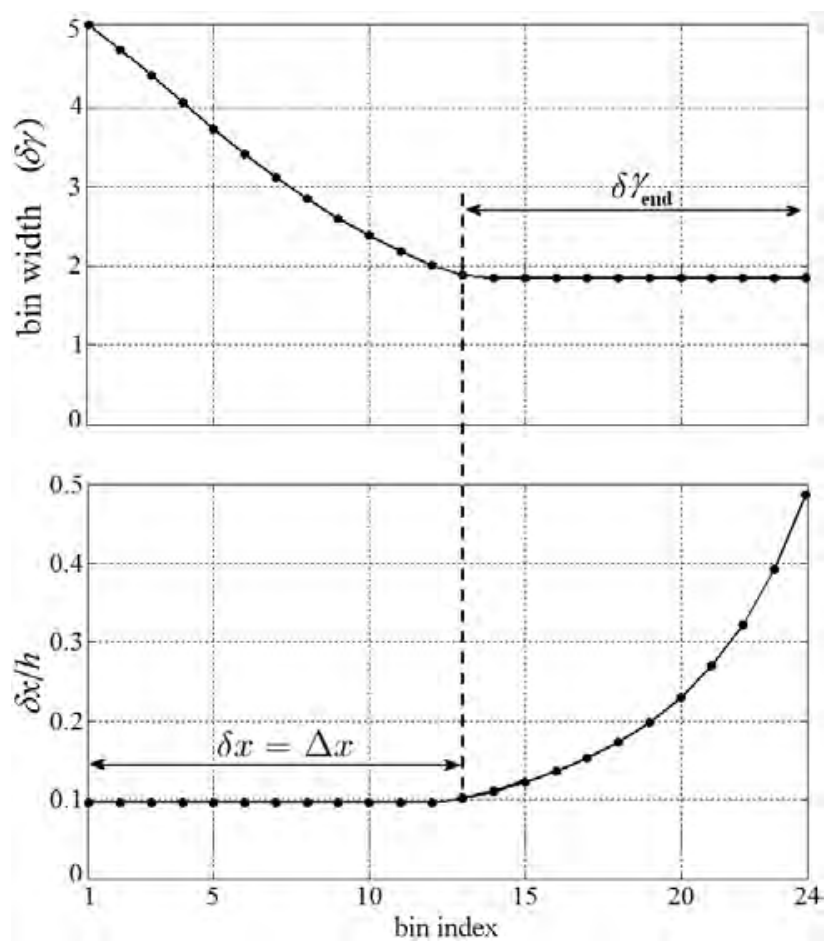

Fig. 5. Binning of the grazing angles in the interval $\left[69^{\circ}, 14^{\circ}\right]$, with $\Delta \gamma_{\max }=5^{\circ}$ and $\delta \gamma_{\text {end }}=2^{\circ}$. (top) Angular bin width $\delta \gamma$. (bottom) Longitudinal extension of the bins.

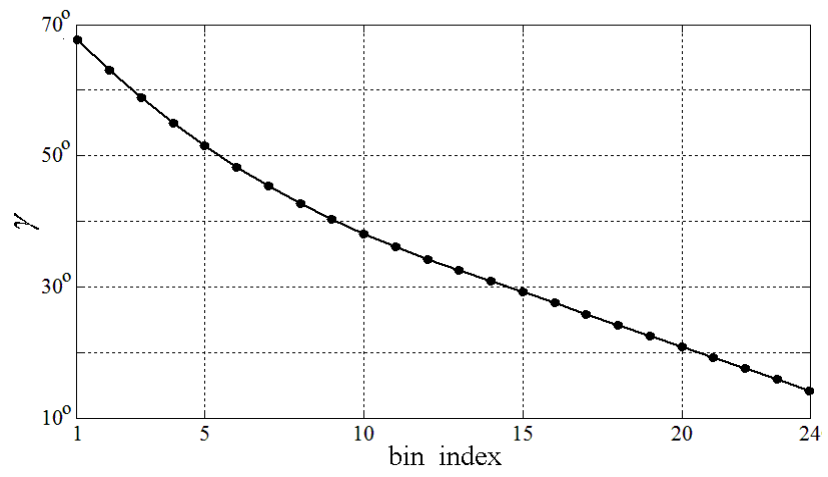

Fig. 6. Grazing angles at the limits between bins.

\subsection{Errors and biases caused by the bottom slope}

The effect of the slope and its orientation on the accuracy of the grazing angles and of the horizontal positioning is analyzed here. One assumes that the relief is smooth enough so that the bottom can be modeled by planes - but not necessarily horizontal - at the range scale of each individual ping. The normal to the seafloor plane (oriented downwards) is given by:

$$
\mathbf{n}=\left[\begin{array}{c}
\sin \alpha \cos \varphi \\
\sin \alpha \sin \varphi \\
\cos \alpha
\end{array}\right],
$$


where $\alpha$ denotes the small positive slope angle between the floor plane and the horizontal $(\cos \alpha=\mathbf{n . z})$, and $\varphi$ $(\in[-\pi, \pi])$ denotes the orientation of the slope (rotation around the z-axis). The intersection of the floor with the plane $y=0$ is the straight line $\left(D_{y}\right)$ (Fig. 7).



Fig. 7. Geometry of the intersection of the floor plane with the central beam.

This line makes the angle $\beta$ with the horizontal plane such that:

$$
\tan \beta=\tan \alpha \cos \varphi
$$

The time delay of the first bottom echo received by the central beam from the point $\mathrm{H}$ yields the apparent depth $h$ used in the mapping process:

$$
\overrightarrow{\mathrm{OH}}=h\left[\begin{array}{c}
\sin \beta \\
0 \\
\cos \beta
\end{array}\right] .
$$

\subsubsection{Grazing angle error}

Let us consider the point $\mathrm{P}$ belonging to the plane bottom, observed at range $r$ of the antennae. Defining the unit vector $\mathbf{u}$ such that $\overrightarrow{\mathrm{OP}}=r \mathbf{u}$, there is

$$
\mathbf{n} \cdot \overrightarrow{H P}=0 \Rightarrow r \mathbf{n} \cdot \mathbf{u}=\mathbf{n} \cdot \overrightarrow{O H} .
$$

The actual grazing angle, $g$, of the ray OP with the plane bottom is such that $\sin g=\mathbf{u}$.n. However, the angle $\gamma$ that is estimated from the time delay of the echoes arrivals $(r)$ and by assuming a horizontal plane bottom at distance $h$ from the sonar is given by $\sin \gamma=h / r$. The relation between this angle $\gamma$ and the actual grazing angle $g$ reads with (3)(4) (5)(6):

$$
\sin g=\mathbf{u} \cdot \mathbf{n}=\sin \gamma \frac{\cos \alpha}{\cos \beta}=\sin \gamma \sqrt{1-\sin ^{2} \alpha \sin ^{2} \varphi} .
$$

There is no error $(\gamma=g)$ when the system runs straight uphill or downhill $(\beta= \pm \alpha$, i.e., $\varphi=0 \bmod \pi)$. Alternately, the error is maximal, $\sin g=\sin \gamma \cos \alpha$, when the trajectory follows an isobath $(\beta=0$, i.e., $|\varphi|=\pi / 2)$. Because the slope is assumed to be small ( $\alpha \ll 1)$, (7) implies that the worst case error $\Delta \gamma=\gamma-g$ is given by

$$
\begin{array}{r}
\sin \Delta \gamma=\frac{\sin ^{2} \alpha \tan \gamma}{\cos \alpha\left(1+\sqrt{1+\tan ^{2} \alpha+\tan ^{2} \alpha \tan ^{2} \gamma}\right)} \\
\Rightarrow \Delta \gamma \approx \frac{\alpha^{2}}{2} \tan \gamma
\end{array}
$$

provided the condition $\alpha^{2} \tan ^{2} \gamma \ll 1$ holds. Although the relative error increases with $\gamma$, it is still negligible up to $\gamma=85^{\circ}$, for which $\Delta \gamma \gamma<1 \%$, with $\alpha=3^{\circ}$. Hence, because the distance $h$ between the sonar and the plane bottom is measured by means of the first bottom echo received with the central beam, the actual grazing angle $g$ is closely approximated by the angle (fig. 7) $\gamma=\arcsin (h / r)$, for whatever the orientation $\varphi$ of the slope is, provided the slope angle $\alpha$ is small.

\subsubsection{Error in the location of the scattering area}

The assumption that the seafloor is a horizontal plane also induces biases in the cartographic projection. For the sake of simplicity, the analysis is performed in the vertical plan $y=0$ containing the trajectory of the platform, i.e., $\mathrm{P}$ belongs here to the straight line $\left(D_{y}\right)$ :

$$
\mathbf{u}=\left[\begin{array}{c}
\cos \zeta \\
0 \\
\sin \zeta
\end{array}\right],
$$

where $\zeta=\gamma-\beta$ denotes the inclination of the ray OP with the horizontal. The scatterer $\mathrm{P}$ is assigned the incorrect abscissa $\mathrm{HP}=x_{p}^{\prime}=r \cos \gamma$ from nadir, instead of the correct one $x_{P}=r \cos \zeta$ (Fig. 7). The longitudinal tracking error is given by:

$$
\Delta x_{P}=x_{P}-x_{p}^{\prime}=\left(1+\frac{\tan \frac{\beta}{2}}{\tan \zeta}\right) z_{p} \sin \beta,
$$

where $z_{P}$ is the depth of the scatterer at point $P$. There is indeed no longitudinal tracking error when the apparent slope $\beta$ is null, i.e., the floor is horizontal $(\alpha=0)$ or the slope is oriented perpendicular to the trajectory $(|\varphi|=\pi / 2)$. Otherwise, because one assumes that the slope $\alpha$ is small (so that $|\beta| \ll 1$ ) and excluding very small grazing angles

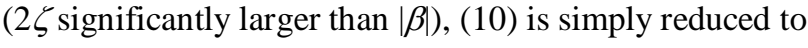

$$
\Delta x_{p} \approx z_{P} \beta \text {. }
$$

Hence, the error in the longitudinal localization does not depend on the depression angle $\zeta$, but only on the apparent slope $\beta$ and on the depth $z_{P}$ of the scanned area. With an average depth of $40 \mathrm{~m}$, and with a slope of $3^{\circ}$, the longitudinal error in the localization of the scattering area reaches $2 \mathrm{~m}$, which is not negligible compared to the size of the resolution cell.

On the other hand, the validity of the local angular backscatter response depends rather on the differential shift of this error versus the angle of view. The first order approximation (11) of $\Delta x_{P}$ (10) does not depend on $\zeta$, so 
the differential shift is one order of magnitude smaller than the shift given by (11). Hence, looking back at (10), the error $\Delta x_{P}$ decreases when $\gamma$ increases so that the maximal differential shift reads as the difference $\Delta_{2} X=\Delta x_{\max }-\Delta x_{\min }$ between the extreme angles of view. Noting that the horizontal range of point $\mathrm{P}$ observed with the depression angle $\zeta$ is $x_{P}(\zeta)=z_{P} / \tan \zeta(10)$ yields

$$
\begin{array}{r}
\Delta_{2} x=\sin \beta \tan \frac{\beta}{2}\left(x_{P}\left(\zeta_{\min }\right)-x_{P}\left(\zeta_{\max }\right)\right) \\
<x_{\max } \sin \beta \tan \frac{\beta}{2}
\end{array}
$$

where $x_{\max }=x_{P}\left(\zeta_{\min }\right)$ is the largest horizontal range from where the bottom can be observed by the system. Taking into account that the apparent slope $\beta$ is small compared to unity, there is finally:

$$
\Delta_{2} x<\frac{\beta^{2} x_{\max }}{2}<\frac{\beta^{2} r_{\max }}{2}
$$

where $r_{\max }$ is the maximum slant range of the system. Eq.(13) is indeed one order of magnitude smaller than (11) . With $r_{\max }=300 \mathrm{~m}$ and $\beta=3^{\circ}$, the slippage in the longitudinal localization of a floor point in the effective range of the viewing angles is not larger than the size of the cell used in the construction of the mosaic images $(40 \mathrm{~cm})$. Although the mapping of the backscatterred echoes can be shifted because of the local slope (11), the differential shift does not impede the local nature of the angular responses that are built.

\section{Method for classification}

The problem consists of grouping the local angular backscatter responses according to a limited number of classes, with the ultimate goal of achieving the seafloor segmentation. Each sample is a vector whose dimension is the number of angular bins (24 with the example in Fig. 6). However, the useful information can be definitively projected into a space whose dimension is much smaller. A classical technique to identify a pertinent basis is the Principal Component Analysis. Classes are defined within the space made of the first eigenvectors.

\subsection{Principal Component Analysis (PCA)}

One processes only the pixels for which the complete angular response in the range of grazing angles displayed in Fig. 6 is available. These points belong indeed to the central band depicted in Fig. 3. Acoustic data are sorted into a matrix $\mathbf{X}=\left[x_{i, j}\right](i=1, \ldots p$ and $j=1, \ldots, n)$, with $p$ rows (pixels) and $n$ columns (angles of view). Each element $x_{i, j}$ of $\mathbf{X}$ represents the intensity that is backscattered by the pixel \#i observed under the grazing angle $\gamma_{j}$. The matrix $\mathbf{X}$ is converted into logarithmic scale $(\mathrm{dB})$, and then rescaled at zero mean and unit variance to build a matrix $\mathbf{Z}$. The correlation matrix $\mathbf{C}=\mathbf{Z}^{\mathrm{T}} \mathbf{Z}$ is computed; its eigenvalues and eigenvectors are found. With data collected at sea (see Section 5), it is found that keeping the first three eigenvectors is quite sufficient to account for the diversity of the responses. All the pixels of the $\mathbf{Z}$ matrix (columns) are then projected on the eigenvectors base. Fig. 11a shows an example of such projection.

\subsection{Cluster identification}

The data distribution in the Principal Component (PC) space is very heterogeneous, and the order of magnitude of the number of points is $10^{6}$. The number and the shapes of the clusters are not known a priori, thus partitioning methods are ruled out. For cluster identification in the PC space, a density-based algorithm is developed. A first set of clusters is identified by means of the level set method [35]. Spurious local minima generate a large number of clusters. This number is eventually reduced by concatenating adjacent clusters whose allowed density gap is userdefined with a single parameter $\varepsilon$.

\subsubsection{Maxima of density}

In order to build the field of density $\rho(\mathbf{r})$, the axis of the PC space are discretized, so that the parallelepipedic volume $V$ that encloses the cloud of data is divided into $N_{c}$ cubic cells. The field $\rho$ is given by the number of data points within each cell, which is eventually smoothed with a spatial filter. The discretized densities are then processed by means of the level set method: the algorithm can be compared to a water level that decreases, revealing isolated peaks, and then the adjacent islets that emerge.

The discretization of the PC space must comply with two constraints: the step should not be too large to avoid the possible fusions of distinct classes; on the other hand, a too small step would spread the data into a large amount of isolated unit clusters. Because the cloud of data does not fill the entire parallelepipedic volume $V$, a proper balance is obtained by setting the number $N_{c}$ of cubic cells equal to the number $N_{s}$ of samples.

Practically, the cells are sorted by decreasing order of density, and then successively assigned a label. This label depends on the labels that may have been already assigned to its 26 cubic neighbors at previous iterations. If no label has been yet assigned to any neighbor, a new cluster label is created: this is a local maximum. If all the labels assigned to the neighbors are identical, then the analyzed cell receives the same label. Otherwise, the neighbors have different labels so that the cell is labeled as a "frontier". Fig. 8 illustrates the process with two clusters in a onedimensional space. Fig. 11b shows an example with data acquired at sea. 


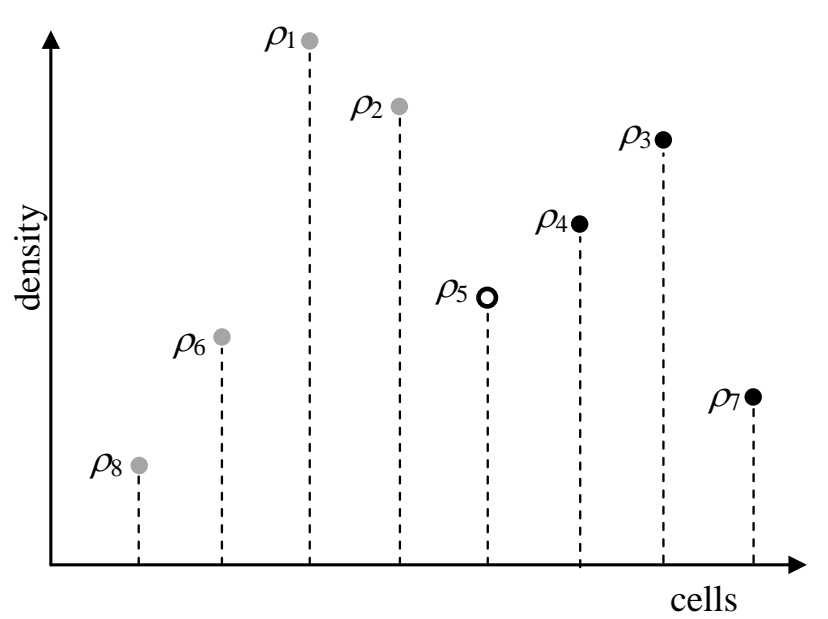

Fig. 8. Cluster identification - Stage 1: Points are indexed according to the decreasing order of density. The gray points belong to the cluster opened by the density $\rho_{1}$, black points belong to the cluster opened by $\rho_{3}$. The white point $\rho_{5}$ is labeled as a "frontier point".

\subsubsection{Merging clusters}

The field $\rho$ has many minor maxima, leading to the creation of a large number of clusters. Fig 9 shows a one dimensional example for which the above described algorithm would create four clusters corresponding to the maximas $a, b, c$ and $d$. Neglecting the minor maxima $a$ and $d$ would reduce the set into two clusters. That is the purpose of the cluster merging process described in the following.

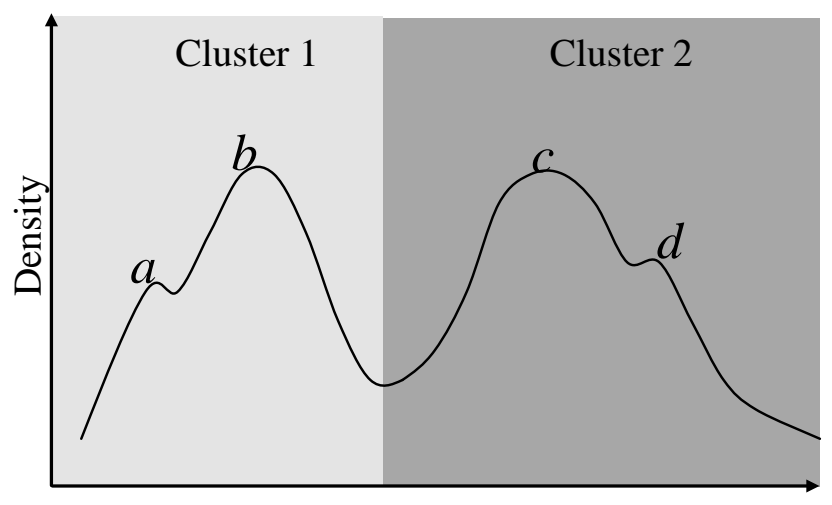

Fig. 9. Minor maxima that lead to identif a large number of clusters at stage 1 .

Let us consider two adjacent clusters, \#i and \#j (i.e., with a common frontier), whose maxima density are noted as, respectively, $\rho_{i}$ and $\rho_{j}$, such that $\rho_{i}>\rho_{j}$ (Fig. 10) Let us denote $\rho_{i j}$ the highest density observed at the frontier between these two clusters, and $d_{i j}=\rho_{j}-\rho_{i j}$ the difference with the smallest of the maxima. The fusion algorithm is based on the principle that two clusters are candidates to merge if the relative difference is small enough, i.e., $d_{i j} / \rho_{j}<\varepsilon$. The parameter $\varepsilon$ is user-defined in the interval ]0,1[. It determines the sensitivity of the merging process: a small value will not allow many connections, resulting in a large number of clusters; conversely, too large a value tends to merge all the clusters. Hence, the determination of the parameter $\varepsilon$ must be supervised ( $\varepsilon=1 / 2$ is chosen with the processed data).

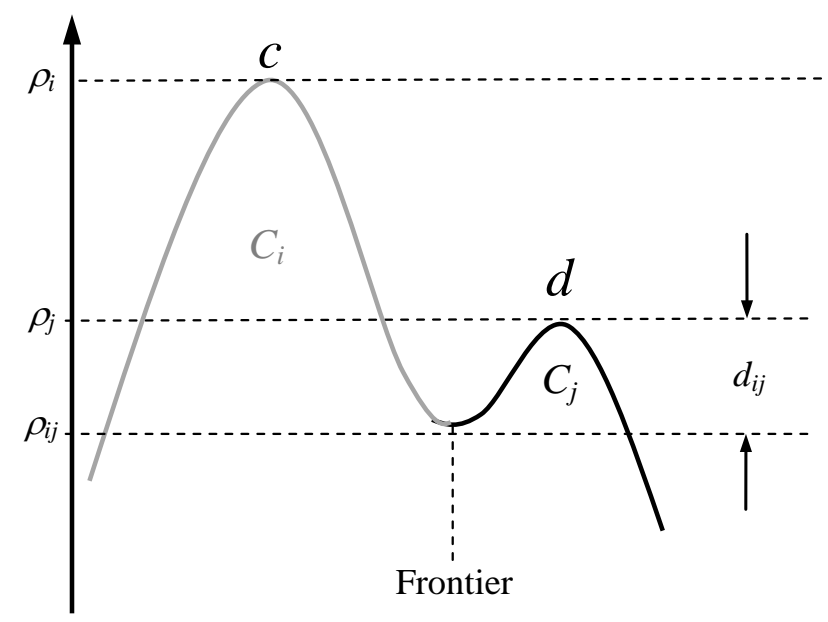

Fig. 10. Parameters to reduce the classes associated to minor maxima. The class $C j$ is a candidate to merge with the class $C i$ if $d_{i j}<\rho_{j} / 2$.

The merging process is implemented hierarchically to avoid ambiguities or degeneration. The clusters are scanned sequentially by decreasing order of mass to check the candidates for fusion with clusters of lesser mass. If such candidates exist, the fusion is performed with the candidate that shares the largest inter-cluster surface with the calling cluster (i.e., of higher mass). This candidate is then not eligible to be called by other classes of higher mass, but still remains in the scanning process to call for possible connection with classes of smaller mass. When the scanning is complete, all the clusters featuring transitive connections are merged. Less than ten clusters result from this process (Fig. 11c).

The barycenter of each cluster can be computed, and the inverse of the conditioning transform described in Section 4.1 gives the typical angular backscatter responses associated with each class. Finally, a segmentation map can be built in assigning to each geo-referenced pixel the color associated to its class in the PC space. 

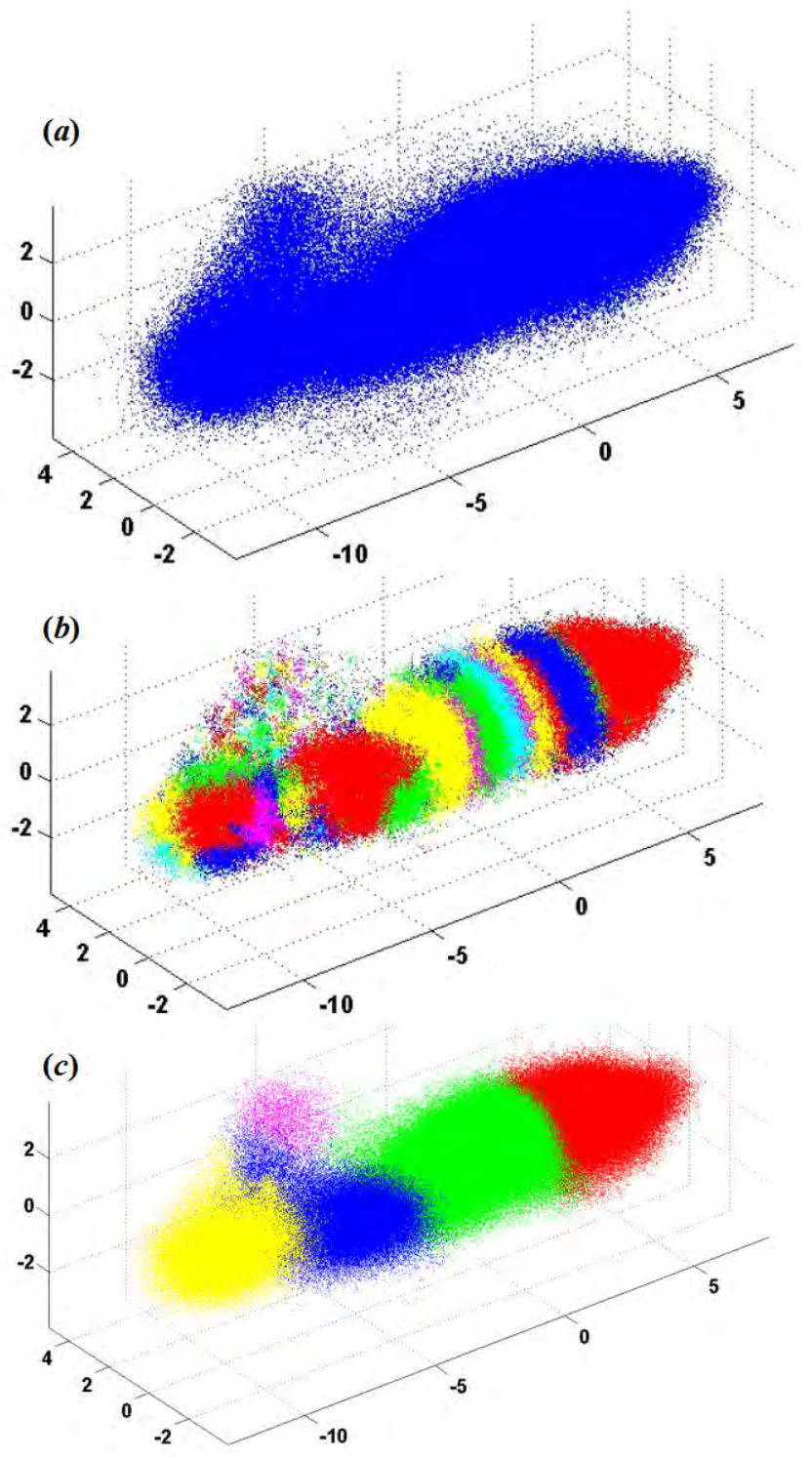

Fig. 11 The parameter $\varepsilon$ must be adjusted empirically. Setting $\varepsilon=1 / 2$ leads to sort most of the processed data into less than ten clusters the Blanes area.

(a) Projection on the first three main components,

(b) clusters derived from the level set method,

(c) clusters remaining after the merging process

\section{Experimental results}

\subsection{Studied areas}

Data were acquired during a three-day campaign (26-28 Oct. 1999) in the Mediterranean Sea off the coast of Barcelona, in the Blanes and Besos regions which feature a large variety of bottom sedimentary characteristics. These areas are well documented [36] [37][38][39]. Sediment samples have been collected (Box Corer, Van Veen Grab, Multicorer) before and during the COSMOS project (see Appendix).


$2^{\circ} 14^{\prime} \mathrm{E}-2^{\circ} 19^{\prime} \mathrm{E}$ ) was covered in 13 transects completing $34 \mathrm{~km}$, with depths ranging between $25 \mathrm{~m}$ and $60 \mathrm{~m}$. The area is divided into three regions: East-Besos (EB), Central-Besos (CB) and West-Besos (WB). EB region is the deepest of them ( $45 \mathrm{~m}$ to $60 \mathrm{~m}$ ). It has small slopes, soft sediment, and presents a well-defined sand body located towards the southeast region of the area. It displays a lenticular shape of $1.5 \mathrm{~km}$ long and $5 \mathrm{~ms}$ thick in crosssections of $3.5 \mathrm{kHz}$ seismic profile [37].

The CB region is characterized by highly variable sediments with subtle transitions. Its main feature is the presence of a large area of anthropogenic sediment deposit of sewers emissions, and a region with abundant trawling marks. The WB region has a soft and uniform relief.

The Blanes area $\left(41^{\circ} 41^{\prime} \mathrm{N}-41^{\circ} 39^{\prime} \mathrm{N} ; 2^{\circ} 47^{\prime} \mathrm{E}\right.$ $2^{\circ} 50 \mathrm{E}$ ) was surveyed in 14 transects, totaling a distance of $25 \mathrm{~km}$. The depth varies between $15 \mathrm{~m}$ and $55 \mathrm{~m}$. The background is diverse, consisting of sandy gravel and rock deposits, with abrupt transitions.

In each studied area (Blanes, EB, CB and WB), the number of pixels is commensurate to $10^{5}$. The range of grazing angles $\left[14^{\circ}, 69^{\circ}\right]$ is divided into 24 angular bins (section 2.3). To limit the error discussed in Section 3.3, areas whose slope is greater than $3^{\circ}$ are excluded (most of the surveyed areas are pretty flat, but for the southeast part of the Blanes zone displayed Fig. 15).

\subsection{Classification and Segmentation}

For producing segmented maps of the surveyed areas, the approach presented in this paper consists of four steps: 1) Construction of a common principal component basis (CPCB) with data belonging to all four areas; 2) the clustering process is performed in the CPCB; 3) All the data collected during the entire survey are projected on the CPCB and then classified.; and finally, 4) the segmentation is performed.

\subsubsection{Basis of reference and clustering}

The first issue is thus to build the vector basis. If using any random data set to perform the PCA that produces this common basis, a potential problem is the possible domination of a particular sediment type, or the lack of diversity. Thus, the data set is made of a supervised selection of patches, featuring a balanced variety of sediments as much as possible. Actually, the supervision task has been prepared by processing each surveyed area independently of each other with the scheme described in section 4 . The resulting local segmentation maps helped to select the various homogeneous areas.

This reduced reference data set is then used to build a reference basis (§ 4.1), i.e., the CPCB. The selection of the sampling patches is performed such that the total volume of the discretized space ( $\S 4.2 .1$ ) in the CPCB contains the projections of all campaign data. Thus, the patch sampling 
is an iterative process. The first eigenvalues of the CPCB are $[0.884,0.030,0.009]$, which shows that $92 \%$ of the information can be described by the space made by the first three eigenvectors. The clustering process is performed on this reference basis, using the method described in $\$ 4.2$ discovering seven main clusters containing 99\% of the data (Fig. 12). The remaining points are distributed in marginal clusters such as the small dark green cluster in figure 12 .

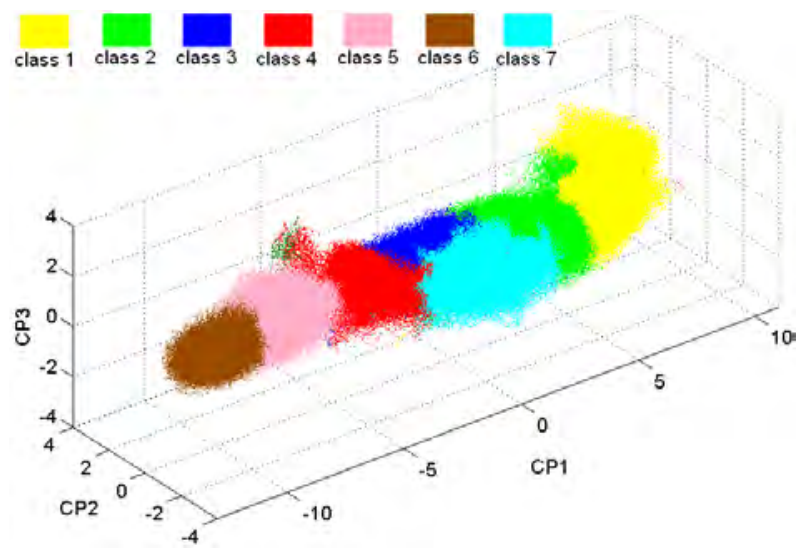

Fig. 12. Clusters in the common principal component basis

Performing the inverse of the barycenter of each cluster, the angular response for each class is obtained, thus determining a set of class-response for all survey areas (Fig. 13). Because of the predominant importance of the first basis vector ( $92 \%$ of the variance) the responses are very similar - with the only exception of Class \#7 -, i.e., differing essentially by the amplitude.

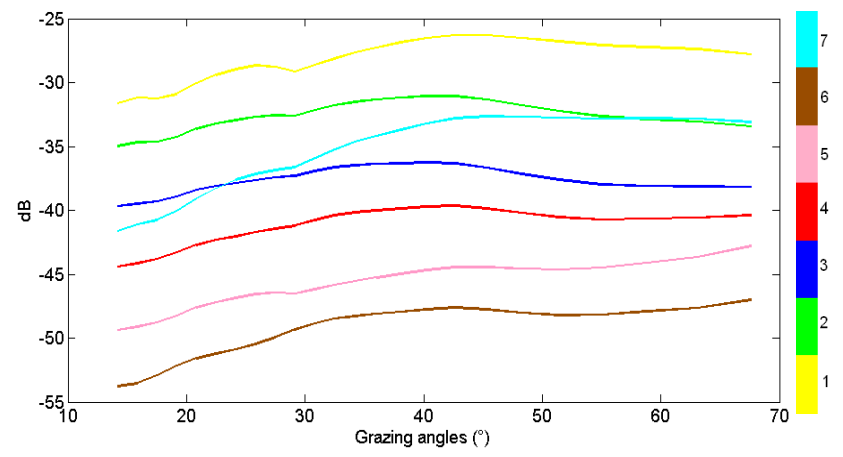

Fig. 13. Angular responses by class (in color).

\subsubsection{Classification}

Each cluster discovered in the previous stage delimits a bounded region, thus defining a class in the CPCB. The classification task is performed by projecting all the collected data of each area onto the common PC basis. The data take the labels associated to the projections. Figures 14-b-c-d-e shows the classification of each of the four zones according to the categories defined by the clusters within the reference area Fig. 14-a. More than 99\% of the data of every zone is classified.

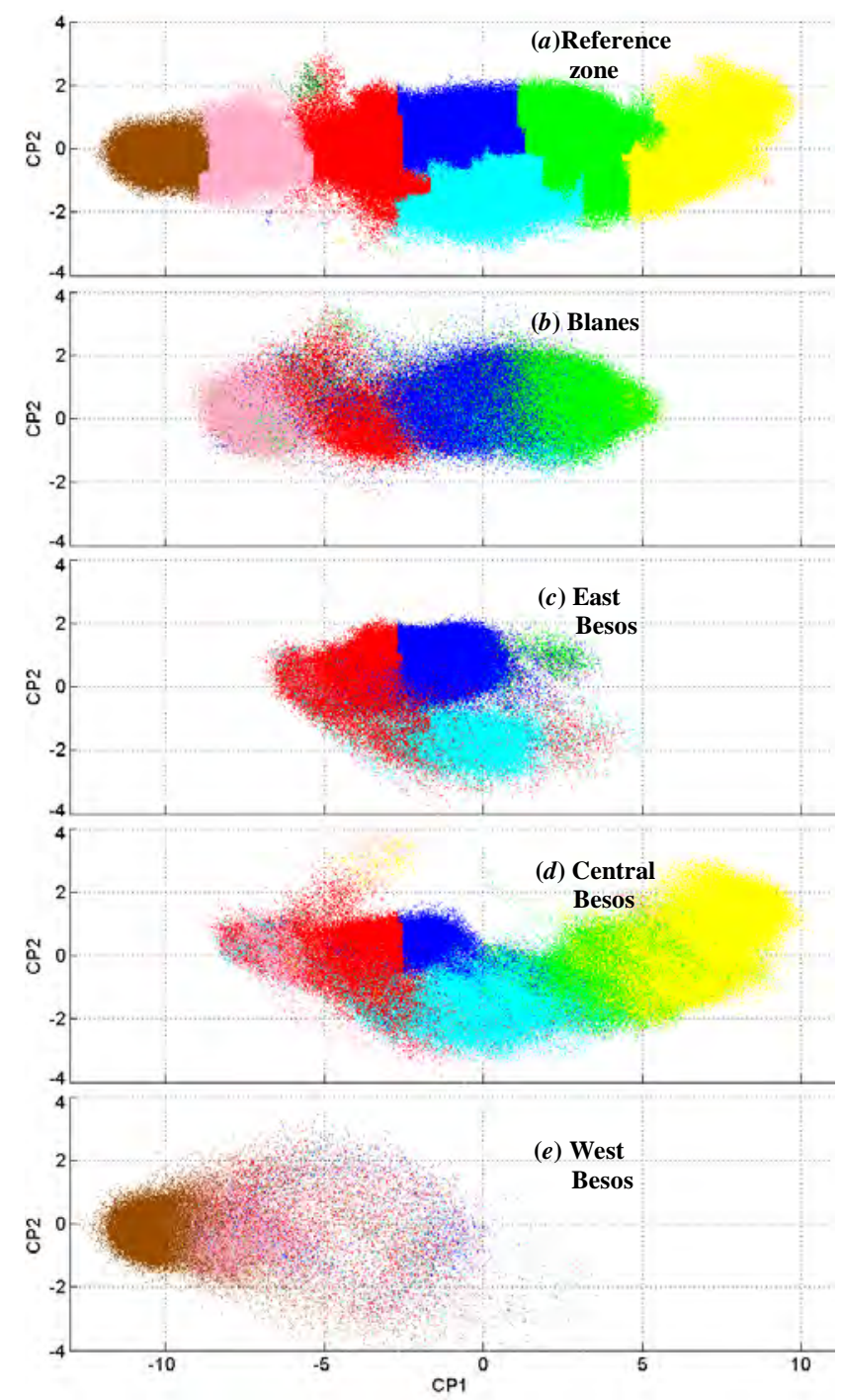

Fig. 14. Projection over the first and second $P C$ and clusters of (a) reference zone, (b) Blanes, (c) EB, (d) CB, (e) WB.

Finally, segmentation is performed by assigning to each classed data the geo-referenced pixel with the color associated with its class. Segmentation maps of Blanes and Besos areas are shown from figure 15 to 20 . 
As already mentioned, the responses of the four classes that are identified in the Blanes area (Classes \#2 to \#5) are quite similar, but for the average reflectivity that spreads in a $12 \mathrm{~dB}$ interval. There is visual evidence of this fact in observing the matching between the segmentation map and the grey levels in the classical backscatter mosaic image (Figs. 15-16). According to the available information, the seabed ranges from rocky (Class \#2) to muddy sand (Class \#5).

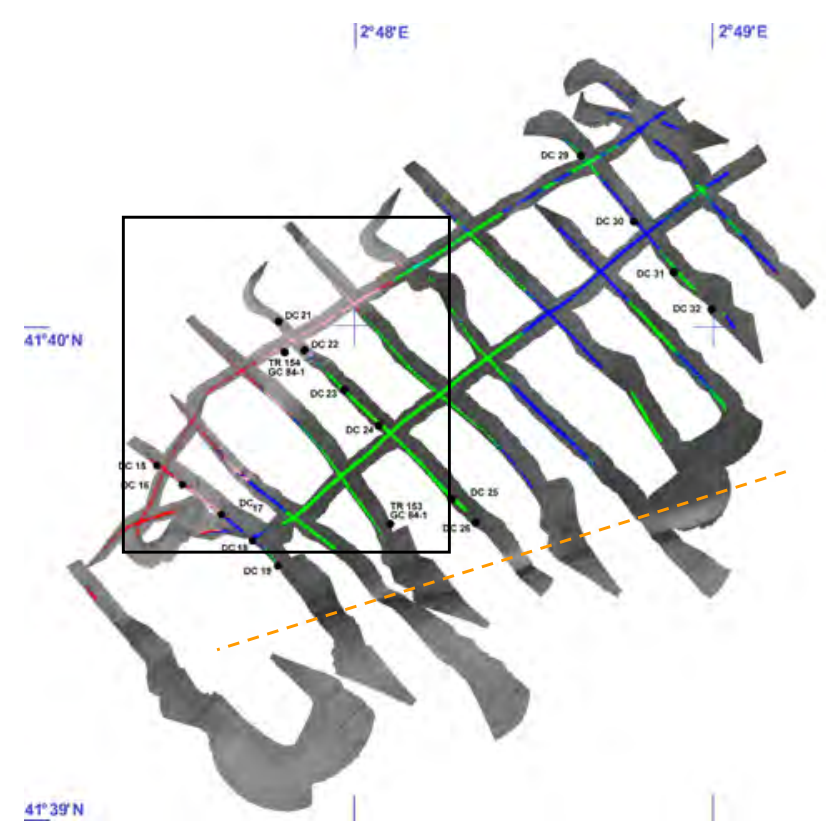

Fig. 15. Blanes Zone. Classes map superimposed to the backscattering image and location of the sediment samples (see Appendix for details of the sampling). South part located below the dashed line is not processed because there is a steep slope $\left(10^{\circ}\right)$ in SW-NE direction.
Compared to the Blanes area, two additional classes are present in the CB area (Figs. 17-18). Class \#1 (yellow) corresponds to soils with very high reflectivity (sediments deposition caused by anthropogenic emissions from Barcelona's sewers). The atypical angular response of Class \#7 (cyan) corresponds to an abrasion platform [36] with abundant trawling marks (Fig. 18).



Fig. 17. Central-Besos Area.

Class map superimposed on the backscattering image and location of the sediment samples. (see Appendix for details of the sampling)

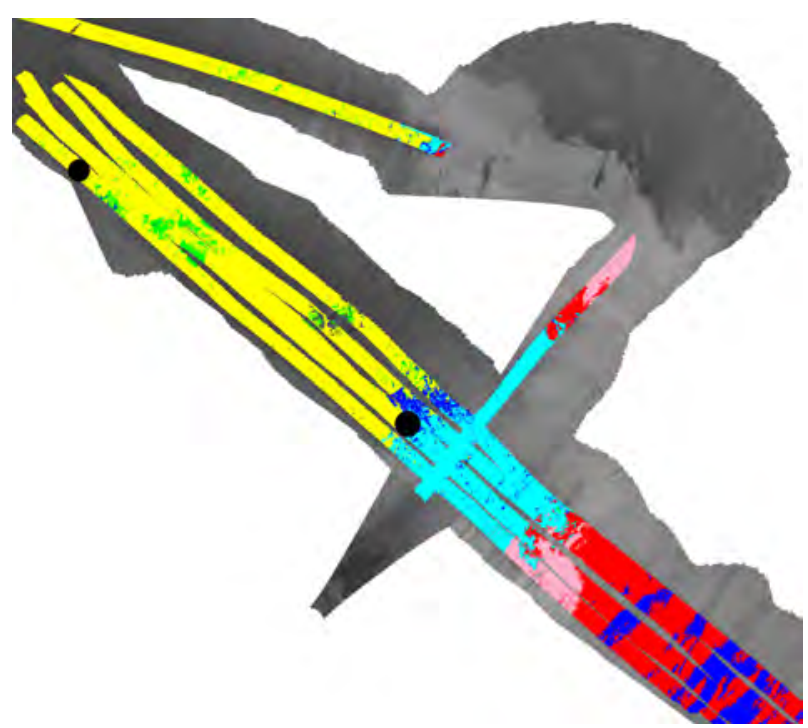

Fig. 18. Central Besos detail. 


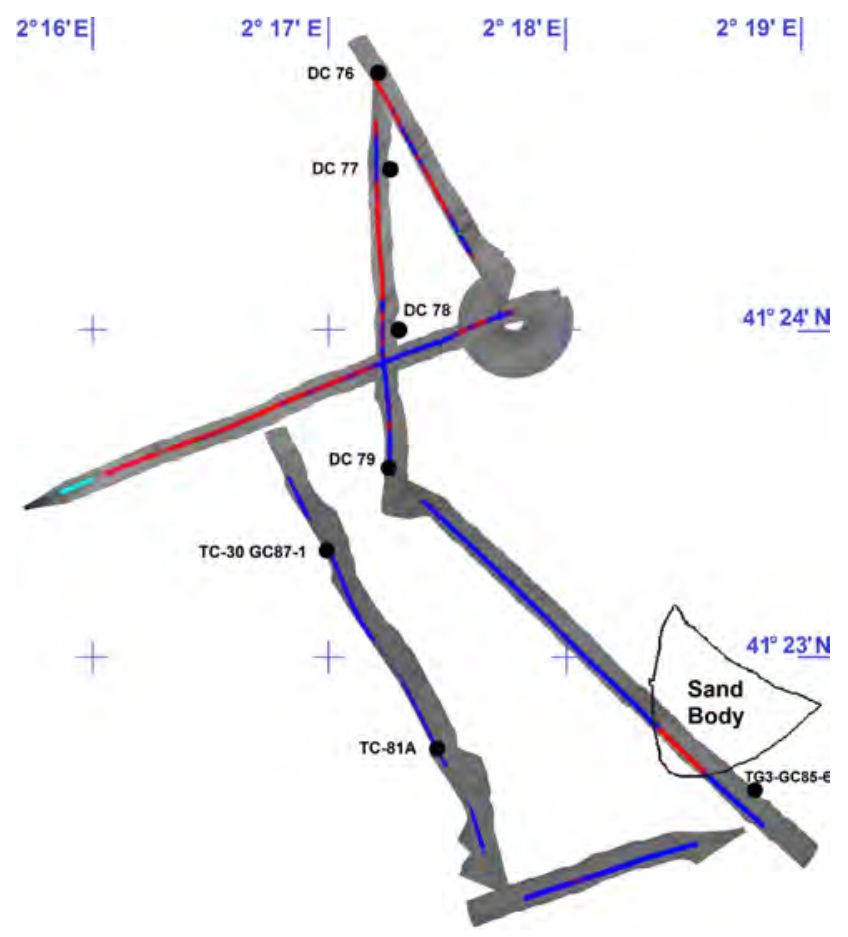

Fig. 19 Location of cores and grabs (see Appendix) superimposed on backscattering image and segmentation map of East-Besos.

Class \#6 (brown) appears only in the WB area (Fig.20). With Class \#5 (pink), these low reflectivity responses correspond to a mixture of fine sand, slit and mud.

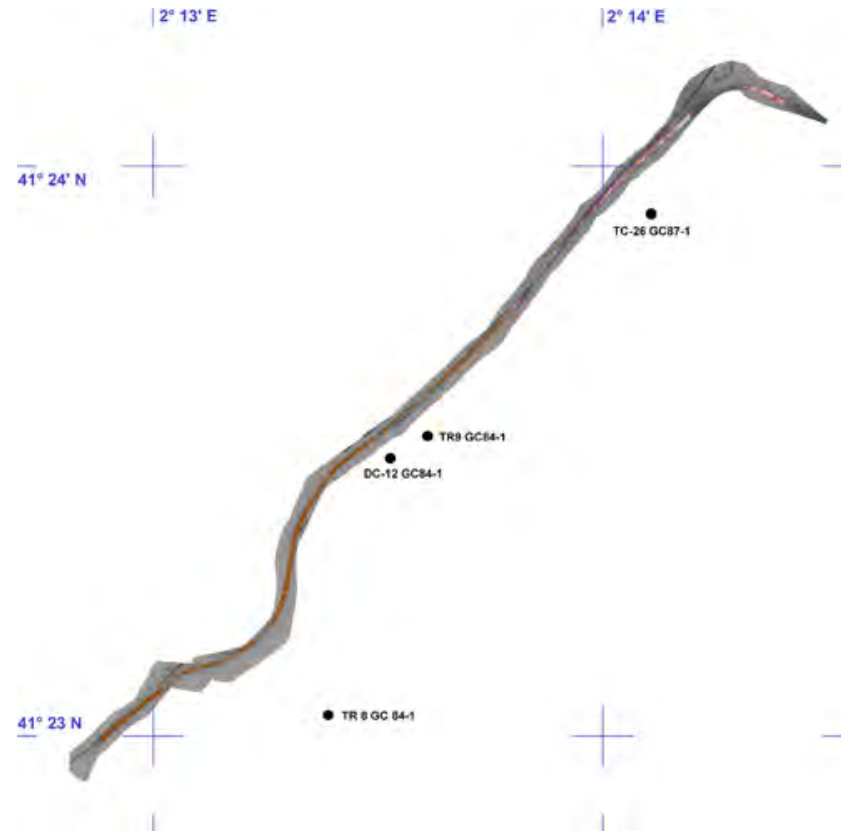

Fig. 20 Location of cores and grabs (see Appendix) superimposed on backscattering image and segmentation map of West-Besos.

\subsection{Ground truth}

Core and grab sediment samples [38] [39] were used to evaluate the quality of the segmentation. Folk scheme [40] is used to classify the samples from the grain size analysis, and the same color code of the responses is associated with each sample (Fig. 21). The geographical location of the samples appears in the figures 15, 17, 19 and 20. The grain-size analysis of the samples and their classification are displayed in the Appendix.



Fig. 21. Folk diagram. The sediment samples are placed in the diagram according to their composition. The color corresponds to the class found with the classification scheme.

Table 1. Folk Sediment-nomenclature

\begin{tabular}{cl}
\hline Symbol & Folk's Name sediment \\
M & Mud \\
sM & Sandy mud \\
(g)M & Slightly gravelly mud \\
(g)sM & Slightly gravelly sandy mud \\
gM & Gravelly mud \\
S & Sand \\
mS & Muddy sand \\
(g)S & Slightly gravelly sand \\
(g)mS & Slightly gravelly muddy sand \\
gmS & Gravelly muddy sand \\
gS & Gravelly sand \\
G & Gravel \\
mG & Muddy gravel \\
msG & Muddy sandy gravel \\
sG & Sandy gravel \\
\hline
\end{tabular}


Seafloor charts and analysis of samples indicates that the sediment in the area where class \#1(yellow) is present corresponds to sediment deposition caused by anthropogenic emissions from Barcelona's sewers. Therefore, class \# 1 is well segmented but is shown separately on the diagram of Fig. 21. The remaining classes can be identified with the help of the Folk scheme. Thus, class \#2 $\rightarrow \mathrm{gS}$; class \#3 $\rightarrow$ (g)S-(g)mS; class \#4 $\rightarrow$ S; class \#5 $\rightarrow \mathrm{mS}-\mathrm{S}$; class \#6 $\rightarrow \mathrm{M}$; class \#7 $\rightarrow \mathrm{M}-\mathrm{g}(\mathrm{M})$.

The classes are grouped into well-defined regions of the Folk triangle with the exception of some points spread within the bottom of the triangle from sM to $\mathrm{mS}$ region and were classed into classes \#3 and \#4. These samples (DC76-79, TG3 and TC81A) belong to the EB zone where abundance of bivalves was reported [37]. This could explain the location of classes \#3 and \#4 ((g)S, (g)mS and S) inside the region corresponding to $\mathrm{sM}$ and $\mathrm{mS}$.

For reference purposes, Figure 22 displays the backscatter indexes given by the APL-UW model [41] at $100 \mathrm{kHz}$. The nomenclature is different from the Folk's one, and the nominal responses of the classes derived from the PCA (Fig. 13) are only relative; so that a straight forward comparison with Fig. 22 is not possible. However, it can be observed that the shape of the APL-UW indexes are very similar in the limited range of grazing angles used in Fig. 13, but for a scaling factor. In addition, the ordering of the strengths is also coherent when comparing both figures.

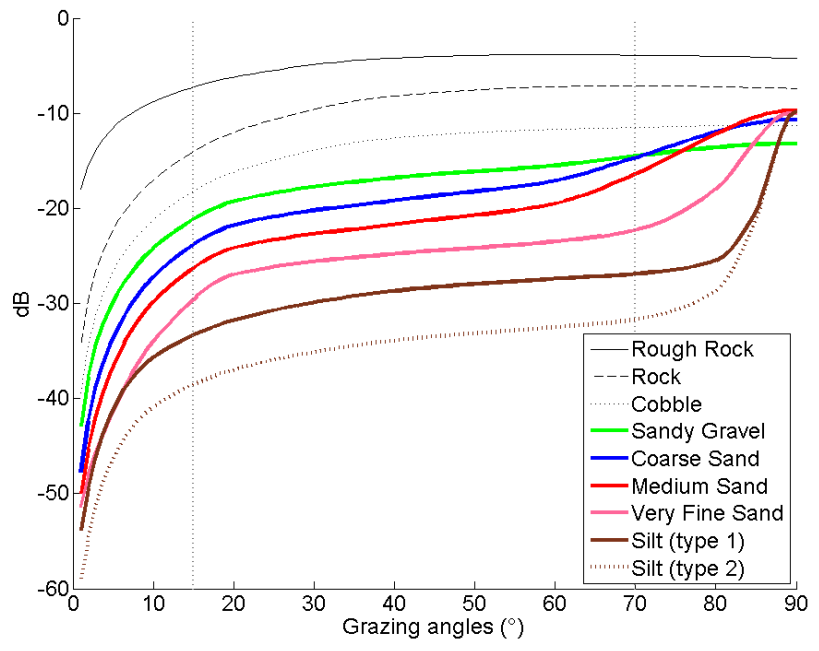

Fig. 22. APL-UW model of backscattering strengths at $100 \mathrm{kHz}$ [41]

\section{Conclusions}

The presented study shows that segmentation maps can be obtained with the local angular responses collected with a forward looking sonar system (the grazing angles are estimated with a simple method based on locally plane seabed). Experimental data collected over known homogeneous areas are selected. This learning data set is used to identify classes without needing taking into account the calibration of the system (sensitivity and directivity in elevation of the antennas). Segmentation of the entire survey is performed by labelling the projected angular responses with these classes.

The limit of the presented results is the lack of dimensional extension observed in the distribution of the responses: most of the extracted information is carried by the first component of the Principal Component Analysis. This means that the shapes of the responses are very similar within the selected range of grazing angles, but for a proportional factor. A better discrimination could be expected with an enlarged range of grazing angles because the largest variations in the backscattered strengths occur at both ends of this range. This is indeed what the theoretical models exhibit (Fig. 22). However, the larger gradients of the responses at the ends of the angular domain strengthen the accuracy requirement in the measured angles. On one hand, it calls for draping the backscattered echoes on a digital terrain model (e.g., [42]). On the other hand, the limited range resolution deteriorates severely the angular resolution close to nadir, whereas the limited signal-tonoise ratio deteriorates the accuracy in the estimated backscattered strength at long range (thus at low grazing angles). In addition, increasing the upper limit of the grazing angles reduces the size of the seafloor for which the complete, local angular response is collected. A way to overcome this limitation is to relax the condition to estimate the local responses, by using different size of pixels in the multilayered images.

The response at large grazing angles cannot be measured outside the central, along-track band. Enlarging the lateral coverage would call for other techniques, e.g., based on processing incomplete angular responses (but using the classes derived from the complete responses). The problem has not been addressed here.

Using a calibrated system to collect the angular responses is indeed an asset as it enables to match the measurements with theoretical models. The capability of the forward-looking system to provide complete - local angular responses should definitively improve the reliability of the comparisons. Another perspective is the joint operation of a forward-looking system with a classical surveying system (e.g., multibeam echosounders), both systems being inter-calibrated. The reference information about the angular responses provided by the forwardlooking system should be helpful in the segmentation of the areas observed with the companion system.

\section{Acknowledgement}

The authors thank Prof. Belén Alonso, Institut de Ciències del Mar-Barcelona, for providing the available sedimentary data of the studied zones. 


\section{References}

[1] Amiri-Simkooei AR, Snellen M, Simons DG. Principal component analysis of Single-Beam Echo-Sounder signal features for seafloor classification. IEEE J Ocean Eng 2011; 36(2): 259-272.

[2] Van Walree PA, Tegowski J, Laban C, Simons DG. Acoustic seafloor discrimination with echo shape parameters: a comparison with the ground truth. Continent Shelf Res 2005; 25: 2273-2293.

[3] Sternlicht DD, de Moustier C. Time-dependent seafloor acoustic backscatter (10-100 kHz). J Acoust Soc Am 2003; 114(5): 2709-2725.

[4] Sternlicht DD, de Moustier C. Remote sensing of sediment characteristics by optimized echo-envelope matching. $J$ Acoust Soc Am 2003; 114(5): 2727-2743.

[5] Pouliquen E, Bergem O, Pace NG. Time-evolution modeling of seafloor scatter. I. Concept. J Acoust Soc Am 1999; 105(6): 3136-3141.

[6] Bergem O, Pouliquen E, Canepa G, Pace NG. Timeevolution modeling of seafloor scatter. II. Numerical and experimental evaluation. J Acoust Soc Am 1999; 105(6): 3142-3150.

[7] Pouliquen E, Lurton X. Identification de la nature du fond de la mer a l'aide de signaux d'échos-sondeurs: I. Modélisation d'échos réverbérés par le fond. Acta Acustica 1994; 2: 113-126, French.

[8] Pouliquen E, Lurton X. Sea-bed identification using echosounder signal. In: proc European Conf on Underwater Acoustics 1992, Elsevier Applied Science: 535-539.

[9] Brown C, Todd BJ, Kostylev VE, Pickrill RA. Image-based classification of multibeam sonar backscatter data for objective surficial sediment mapping of Georges Bank, Canada. Cont Shelf Res 2011; 31: 110-119.

[10] Celik T, Tjahjadi T. A novel method for sidescan sonar image segmentation. IEEE J Ocean Eng 2011; 36(2): 186194.

[11] Blondel Ph, Gómez Sichi O. Textural analyses of multibeam sonar imagery from Stanton Banks, Northern Ireland continental shelf. Appl Acous 2009; 70: 1288-1297.

[12] Karoui I, Fablet R, Boucher J, Augustin JM. Seabed segmentation using optimized statistics of sonar textures. IEEE Trans Geosci Remote Sens 2009; 47(6): 1621-1631.

[13] Blondel Ph, Parson LM. Quantitative characterisation of geological processes using sidescan sonar imagery. In IEE Colloquium on Underwater Applications of Image Processing 1998; 2: 1-6.

[14] Subramaniam S, Barad H, Martinez AB, Bourgeois B. Seafloor characterization using texture. In Proceedings IEEE Southeastcon 1993; I: 1-8.

[15] Reed TB, Hussong DM. Digital image processing techniques for enhancement and classification of SeaMARC II Side-Scan Sonar imagery. J Geophys Res 1998; 94(6): 7469-7490.

[16] Pican N, Trucco E, Ross M, Lane DM, Petillot Y, Tena Ruiz I. Texture analysis for seabed classification: Cooccurrence Matrices vs self-organizing maps. In Proc IEEE/OES OCEANS'98 1998; 1: 424-428.

[17] Dugelay S. Deep seafloor characterization with Multibeam Echosounders using image segmentation and angular acoustic variations. In Proc MTS/IEEE OCEANS'96 1996; 3: $1545-1550$.

[18] Fonseca L, Brown CJ, Calder B, Mayer L, Rzhanov Y. Angular range analysis of acoustic themes from Stanton Banks Ireland: A link between visual interpretation and multibeam echosounder angular signatures. Appl Acoust 2009; 70: 1298-1304.

[19] Hughes-Clarke JE. Toward remote classification using the angular response of acoustic backscattering: a case study from multiple overlapping GLORIA data. IEEE J Ocean Eng 1994; 19(1): 112-127.

[20] de Moustier C, Alexandrou D. Angular dependence of 12 kHz seafloor acoustic backscatter. J Acoust Soc Am 1991; 90(1): 522-531.

[21] Hamilton LJ, Parnum I. Acoustic seabed segmentation from direct statistical clustering of entire multibeam sonar backscatter curves. Cont Shelf Res 2011; 31: 138-148.

[22] Fonseca L, Mayer L. Remote estimation of surficial seafloor properties through the application Angular Range Analysis to multibeam sonar data. Mar Geophys Res 2007; 28: 119-126.

[23] Chakraborty B, Hagen RA, Schenke HW. Determining seabed backscatter parameters using Hydrosweep System. In Proc 3de Eur Conf Underwater Acoustics 1996; I: 99104.

[24] Chakraborty B, Schenke HW, Kodagali V, Hagen RA. Seabottom characterization using multibeam echosounder angular backscatter: an application of the composite roughness theory. IEEE Trans Geosci Remote Sens 2000; 38(5): 2419-2422.

[25] Bentrem FW, Sample J, Kalcic MT, Duncan M. Highfrequency acoustic sediment classification in shallow water. In Proc MTS/IEEE Oceans'02 2002; 1: 7-11.

[26] Chakraborty B, Kodagali V, Baracho J. Sea-floor classification using Multibeam Echo-Sounding angular backscatter data: A real-time approach employing hybrid neural network architecture. IEEE J Ocean Eng 2003; 28(1): 121128.

[27] Hamilton LJ. A bibliography of acoustic seabed classification. CRC for coastal zone, estuary and waterway management Technical report No 27 2005; http://www.ozcoasts.org.au/pdf/CRC/27Hamilton_Acoustic_Biblio.pdf

[28] Hammerstad E, Åsheim S, Nilsen K, Bodholt H. Advances in multibeam echo sounder technology. In Proc OCEANS '93 Engineering in Harmony with Ocean 1993; 1: 482-487.

[29] de Moustier C. State of the art in swath bathymetry survey systems. Int Hydro Rev 1988; 65: 25-54.

[30] de Moustier C, Malsumoto H. Seafloor acoustic remote sensing with multibeam echosounders and bathymetric sidescan sonar systems. Mar Geophys Res 1993; 15: 27-42.

[31] Augustin JM, Le Suave R, Lurton X, Voisset M, Dugeley $\mathrm{S}$, Catra C. Contribution of the multibeam acoustic imagery to the exploration of the sea-bottom. Examples of SOPACMAPS 3 and ZoNeCo 1 cruises. Mar Geophys Res 1996; 18: 459-486.

[32] Cervenka P. Characterization and observation of de seafloor with a new multibeam front-scan sonar system (COSMOS). In Proc 3rd European Marine Science and Technology Conference 1998; III: 1287-1297.

[33] Cervenka P, Marchal J. Imaging with a new multi-look front-scan sonar system. Acta Acustica 2004; 90: 38-48.

[34] Janvrin Ph. Sonar frontal pour l'imagerie par synthese noncoherente et la bathymetrie. Thèse de doctorat de l’Université Paris 6, 2000, French.

[35] Wang X-F, Huang D-S. A Novel Density-Based Clustering Framework by Using Level Set Method. IEEE Trans Knowledge and Data Eng 2009; 21(11): 1515-1531.

[36] COSMOS Final report on task 1.2, Sea trials specifications; by Institut de Ciències del Mar, Barcelona, March 2001. 
[37] COSMOS Final Report on Task 6.1, Analysis And Interpretation Of Results by ICM-CSIC \& IFREMER, March 2001

[38] COSMOS Final Report on Task 3.1, Research Cruise Reports\& ROSCOP by ICM-CSIC \& IFREMER, March 2001

[39] Departament de Geologia Marina de l'Institut de Ciències del Mar (ICM), Barcelona.

http://www.icm.csic.es/geo/gma/SurveyMaps.

Last verification march 19th 2014.
[40] Folk RL. The distinction between grain size and mineral composition in sedimentary rock nomenclature. $J$ Geol 1954; 62(4): 344-359.

[41] APL-UW High- Frequency Ocean Environmental Acoustics Models Handbook (APL-UW TR 9407), Seattle, WA: Applied Physics Laboratory, University of Washington, 1994.

[42] Cervenka P, de Moustier C, Lonsdale PF. Geometric corrections on sidescan sonar images based on bathymetry. Application with SeaMARC II and Sea Beam data. Mar Geophys Res 1994; 16: 365-383.

\section{Appendix}

Table A.1 Location, sediment composition and classification of samples provided by the ICM

\begin{tabular}{|c|c|c|c|c|c|c|c|c|}
\hline Long. & Latitude & Sample & Gravel & Sand\% & Silt \% & Clay\% & Folk & Class \\
\hline \multicolumn{9}{|c|}{ BESOS East } \\
\hline $2^{\circ} 17^{\prime} 00^{\prime \prime}$ & $41^{\circ} 23^{\prime} 18^{\prime \prime}$ & TC-30 GC-87-1 & 4 & 71 & \multicolumn{2}{|c|}{20} & (g)sM & 3 \\
\hline $2^{\circ} 18^{\prime} 47^{\prime}$, & $41^{\circ} 22^{\prime} 39^{\prime \prime}$ & TG-3 GC-85-6 & \multicolumn{4}{|c|}{ bio-muddy sands } & $\mathrm{mS}$ & 3 \\
\hline \multicolumn{9}{|c|}{ BESOS central } \\
\hline $2^{\circ} 15^{\prime} 32^{\prime \prime}$ & $41^{\circ} 23^{\prime} 44^{\prime \prime}$ & TR-222 GC-84-1 & \multicolumn{5}{|c|}{ fetid muds } & 1 \\
\hline $2^{\circ} 16^{\prime} 14^{\prime \prime}$ & $41^{\circ} 23^{\prime} 11^{\prime \prime}$ & TC-3 GC-87-1 & 3 & 57 & \multicolumn{2}{|c|}{40} & $(\mathrm{~g}) \mathrm{mS}$ & \begin{tabular}{l|l}
4 & 3 \\
\end{tabular} \\
\hline $2^{\circ} 15^{\prime} 51^{\prime \prime}$ & $41^{\circ} 23^{\prime} 19^{\prime \prime}$ & TG-10 GC-87-1 & \multicolumn{4}{|c|}{ Brown muds (top and bottom) } & $\mathrm{M}$ & 7 \\
\hline $2^{\circ} 15^{\prime} 50^{\prime \prime}$ & $41^{\circ} 23^{\prime} 27^{\prime \prime}$ & TC-4 GC-87-1 & 0 & 4 & \multicolumn{2}{|c|}{96 (black mud) } & M & 7 \\
\hline \multicolumn{9}{|c|}{ BESOS West } \\
\hline & & & Gravel & Sand & Silt & Clay & Folk & \\
\hline $2^{\circ} 14^{\prime} 14^{\prime \prime}$ & $41^{\circ} 23^{\prime} 52^{\prime \prime}$ & TC-26 GC-87-1 & 0 & 10 & \multicolumn{2}{|c|}{90} & M & \begin{tabular}{l|l}
6 & 5 \\
\end{tabular} \\
\hline $2^{\circ} 13^{\prime} 32^{\prime \prime}$ & $41^{\circ} 23^{\prime} 26^{\prime \prime}$ & DC 12GC 84-1 & 0 & 5 & 59 & 36 & M & 6 \\
\hline $2^{\circ} 13^{\prime} 37^{\prime \prime}$ & $41^{\circ} 23^{\prime} 30^{\prime \prime}$ & TR 9 GC 84-1 & 0 & 8 & 65 & 27 & $\mathrm{M}$ & 6 \\
\hline $2^{\circ} 13^{\prime} 24^{\prime \prime}$ & $41^{\circ} 23^{\prime} 03^{\prime \prime}$ & TR 8 GC 84-1 & 0 & 7 & 51 & 42 & $\mathrm{M}$ & 6 \\
\hline \multicolumn{9}{|l|}{ BLANES } \\
\hline $2^{\circ} 48^{\prime} 11^{\prime \prime}$ & $41^{\circ} 39^{\prime} 26^{\prime \prime}$ & TR 153 GC 84-1 & 12 & 85 & 2 & 1 & gS & 2 \\
\hline $2^{\circ} 47^{\prime} 51^{\prime \prime}$ & $41^{\circ} 39^{\prime} 56^{\prime \prime}$ & TR 154 GC 84-1 & 1 & 97 & \multicolumn{2}{|c|}{2} & S & 5 \\
\hline
\end{tabular}


Table A.2 Location, sediment composition and classification of samples collected in COSMOS campaign. East-Besos area.

\begin{tabular}{|c|c|c|c|c|c|c|c|c|c|}
\hline Long. & Latitude & Sample & Special characteristics & Gravel & Sand & Silt & Clay & Folk & Cass \\
\hline $2^{\circ} 17^{\prime} 12^{\prime \prime}$ & $41^{\circ} 24^{\prime} 48^{\prime \prime}$ & DC-76 & \multirow{5}{*}{$\begin{array}{l}\text { abundant remains of bivalves } \\
\text { and turritellas }\end{array}$} & 0 & 9 & 61 & 30 & $\mathrm{sM}$ & 4 \\
\hline $2^{\circ} 17^{\prime} 16^{\prime \prime}$ & $41^{\circ} 24^{\prime} 28^{\prime \prime}$ & DC-77 & & 0 & 28 & 54 & 18 & $\mathrm{sM}$ & 3 \\
\hline $2^{\circ} 17^{\prime} 19^{\prime \prime}$ & $41^{\circ} 24^{\prime} 02^{\prime \prime}$ & DC-78 & & 0 & 42 & 38 & 16 & $\mathrm{sM}$ & 4 \\
\hline $2^{\circ} 17^{\prime} 16^{\prime \prime}$ & $41^{\circ} 23^{\prime} 35^{\prime \prime}$ & DC-79 & & 0 & 25 & 57 & 18 & $\mathrm{sM}$ & 3 \\
\hline $2^{\circ} 17^{\prime} 25^{\prime}$, & $41^{\circ} 22^{\prime} 44^{\prime \prime}$ & TC-81A & & 0 & 59 & 24 & 13 & $\mathrm{mS}$ & 3 \\
\hline
\end{tabular}

Table A3. Location, sediment composition and classification of samples collected in COSMOS campaign. Blanes area.

\begin{tabular}{|c|c|c|c|c|c|c|c|c|}
\hline Long. & Latitude & Sample & Gravel & Sand & Silt & Clay & Folk & Class \\
\hline $2^{\circ} 47^{\prime} 24^{\prime \prime}$ & 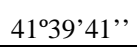 & DC15 & 0 & 98 & 2 & 0 & $\mathrm{~S}$ & 4 \\
\hline $2^{\circ} 47^{\prime} 28^{\prime \prime}$ & 41'39’37', & DC16 & 0 & 98 & 2 & 0 & S & 4 \\
\hline $2^{\circ} 47^{\prime} 34^{\prime \prime}$ & 41'39'35', & DC17 & 1 & 81 & 18 & 0 & $\mathrm{mS}$ & 5 \\
\hline $2^{\circ} 47^{\prime} 39^{\prime \prime}$ & 41'39'31', & DC18 & 2 & 96 & 2 & 0 & (g) $\mathrm{mS}$ & 3 \\
\hline $2^{\circ} 47^{\prime} 44^{\prime \prime}$ & 41'39'29', & DC19 & 17 & 82 & 2 & 0 & gS & 2 \\
\hline $2^{\circ} 47^{\prime} 43^{\prime \prime}$ & $41^{\circ} 40^{\prime} 01^{\prime \prime}$ & DC21 & 0 & 96 & 4 & 0 & $\mathrm{~S}$ & 5 \\
\hline $2^{\circ} 47^{\prime} 49^{\prime \prime}$ & 41'39'56', & DC22 & 0 & 97 & 3 & 0 & $\mathrm{~S}$ & 5 \\
\hline $2^{\circ} 47^{\prime} 53^{\prime \prime}$ & 41'39'52,' & DC23 & 5 & 91 & 4 & 0 & gS & 2 \\
\hline $2^{\circ} 48^{\prime} 01^{\prime \prime}$ & 41'39'47', & DC24 & 21 & 77 & 2 & 0 & gS & 2 \\
\hline $2^{\circ} 48^{\prime} 07^{\prime \prime}$ & 41'39'43,' & DC25 & 16 & 81 & 3 & 0 & gS & 2 \\
\hline $2^{\circ} 48^{\prime} 13^{\prime \prime}$ & 41'39'39', & DC26 & 49 & 45 & 6 & 0 & $\mathrm{msG}$ & 2 \\
\hline $2^{\circ} 48^{\prime} 34^{\prime \prime}$ & $41^{\circ} 40^{\prime} 20^{\prime \prime}$ & DC29 & 29 & 69 & 2 & 0 & gS & 2 \\
\hline $2^{\circ} 48^{\prime} 42^{\prime \prime}$ & $41^{\circ} 40^{\prime} 15^{\prime \prime}$ & DC30 & 4 & 93 & 2 & 0 & (g)S & 3 \\
\hline $2^{\circ} 48^{\prime} 50^{\prime \prime}$ & $41^{\circ} 40^{\prime} 08^{\prime \prime}$ & DC31 & 14 & 84 & 1 & 0 & gS & 3 \\
\hline $2^{\circ} 48^{\prime} 55^{\prime \prime}$ & $41^{\circ} 40^{\prime} 02^{\prime \prime}$ & DC32 & 12 & 86 & 2 & 0 & gS & 3 \\
\hline
\end{tabular}

